\title{
A língua em funcionamento nas práticas discursivas
}

\section{Language functioning in discursive practices}

\author{
Adair Vieira Gonçalves* \\ Universidade Federal da Grande Dourados - UFGD \\ Dourados - Mato Grosso do Sul/Brasil \\ Cláudia Lopes Nascimento Saito** \\ Universidade Estadual do Centro-Oeste - UNICENTRO \\ Guarapuava - Paraná/Brasil \\ Elvira Lopes Nascimento*** \\ Universidade Estadual de Londrina - UEL \\ Londrina - Paraná/Brasil
}

\begin{abstract}
RESUMO: Fundamentos do quadro epistemológico do interacionismo sociodiscursivo da Escola de Genebra e da vertente funcionalista de estudos da linguagem ecoam nas ideias pressupostas em três documentos oficiais: Proposta Curricular de Língua Portuguesa do Estado de São Paulo (PCLP), Diretrizes curriculares da Educação Básica do estado do Paraná (DCE) e dos Parâmetros Curriculares Nacionais (PCN), considerando que esses documentos postulam, como eixo do trabalho pedagógico, as práticas discursivas nos diferentes contextos de uso da língua. $\mathrm{O}$ enfoque na língua contextualizada nas práticas sociais constitui um novo paradigma para a formação de professores e para a didatização de tais práticas. Nesse sentido, os autores dão a sua contribuição, apresentando proposta de modelização didática de uma prática social que contribua para a elaboração de atividades didáticas em que se articulem aspectos linguísticos e discursivos emergentes do funcionamento da linguagem.
\end{abstract}

PALAVRAS-CHAVE: Interacionismo sociodiscursivo, Funcionalimo, análise linguística

ABSTRACT: The School of Geneva sociodiscursive interactionism epistemology and the functional versant of studies of language echoed on the presupposed ideas in three official documents: the State of São Paulo Portuguese Curricular Proposal (PCLP), the State of Paraná Basic education Curricular Directives (DCE) and the National Curricular Parameters (PCN). These documents postulate discursive practices in different contexts of language use as the axis for pedagogic

\footnotetext{
*adairgoncalves@uol.com.br

**cln_saito@yahoo.com.br

***elopes@sercomtel.com.br
} 
work. The approach based on contextualized language in social practices constitutes a new paradigm for teacher training and the didactization of such practices. To that end, the authors give their contribution by presenting a proposal for didactic modeling of a social practice which contributes to the elaboration of didactic activities in which articulate linguistic and discursive aspects emerging from the functioning of language can be found.

KEYWORDS: Sociodiscursive interactionism, Functionalism, linguistic analysis

\section{Introdução}

A partir da década de 80, pesquisas linguísticas começavam a oferecer saídas / sugestões para o ensino de Língua Portuguesa no Ensino Básico. Parte das prescrições está nos documentos oficiais, tais como as propostas curriculares para o ensino de língua portuguesa do estado de São Paulo cuja edição primeira é de 1986 e a mais recente é de 2008. Aparício (2006) e Silva (2010) salientam que há, na década de 90, uma série de pesquisas / trabalhos acadêmicos que apontam para a renovação do ensino de gramática nas escolas, criticando o ensino tradicional pautado na frase descontextualizada e nas regras de uso da gramática normativa. Antes disso, o ensino gramatical parecia adequado e era oferecido a todas as camadas da população. A variedade linguística falada era muito próxima à desejada pela escola.

Vários linguistas, a partir do desenvolvimento de pesquisas em importantes universidades brasileiras, começaram a apresentar resultados de reflexões e a apontar falhas na abordagem da gramática das décadas anteriores. Entre as críticas ao ensino tradicional de língua materna soam, de forma contundente, os PCN ao denunciarem:

[a] desconsideração da realidade e dos interesses dos alunos, a excessiva escolarização das atividades de leitura e de escrita, o uso do texto como expediente para ensinar valores morais e como pretexto para o tratamento de aspectos gramaticais; a excessiva valorização da gramática normativa e a insistência nas regras de exceção, com o consequente preconceito contra as formas de oralidade e as variedades não-padrão; o ensino descontextualizado da metalinguagem, normalmente associado a exercícios mecânicos de identificação de fragmentos linguísticos associados em frases soltas; apresentação de uma teoria gramatical inconsistente - uma espécie de gramática tradicional mitigada e facilitada. (BRASIL, 1998, p.18).

A partir das questóes acima, neste artigo, trataremos do Ensino de gramática associando o ensino de gêneros textuais defendidos pelos $\mathrm{PCN}$ e a 
relação com a perspectiva funcionalista da linguagem, cujos estudos denominamos hoje como funcionalistas. ${ }^{1}$ Para atingirmos tais objetivos, o presente trabalho apresenta a seguinte configuração: no primeiro tópico, traçamos um breve histórico compreendendo a visão estritamente formal e reducionista do fenômeno linguístico no nível da frase, à mudança de perspectiva que se convencionou chamar de "virada pragmática", defendida pelos documentos oficiais e propostas curriculares. No segundo, trazemos considerações da teoria de Bakhtin/Voloshinov (1995[1919]), Bronckart (2003, 2006) e Neves (2000, 2004, 2006) a fim de fazer uma contraposição entre os estudos formalistas e sociointeracionistas. Em seguida, nos aprofundamos nos preceitos teóricos do Funcionalismo e constatamos seus postulados nos PCN (1998). Finalmente, apresentamos uma proposta de análise de um determinado gênero discursivo à luz das orientaçôes funcionalistas a partir de um corpus de cinco textos de gêneros da esfera da publicidade que fazem parte da Edição Especial da revista Veja, de dezembro de 2001, do ano 34, n. ${ }^{\circ}$ 51, intitulada Guia para fazer o bem, disponível para o leitor no seu site (www.veja.com.br/acervodigital/home.asp).

\section{A articulação da abordagem funcionalista ao estudo da língua}

Como salientado anteriormente, nos PCN, nas DCE e na PCLP encontram-se referências explícitas de que o foco do ensino de LP são as práticas de uso da linguagem e isso engloba o sistema de signos utilizados por uma comunidade nas diferentes esferas de comunicação. ${ }^{2}$ Em outras palavras,

\footnotetext{
${ }^{1}$ Os estudos funcionalistas são representados particularmente pela Escola de Praga com Nikolai Trubetzkoy (1890-1938); Roman Jakobson (1896-1982) e a influente teoria das funções da linguagem; a Escola de Copenhague com Louis Hjelmslev (18991965) chegando à Escola de Londres com John Firth (1890-1960), a quem se deve, segundo Marcuschi (2008), a sistematização da noção de contexto de situação.

${ }^{2}$ Para Bakhtin/ Voloshinov (1995[1919]), a mudança de esfera modifica, altera ou subverte as relaçóes implicadas nos discursos que constituem um texto ou um conjunto de textos. Esse aspecto está sinalizado na passagem em Marxismo e Filosofia da Linguagem: "no domínio dos signos, isto é, na esfera ideológica, existem diferenças profundas, pois este domínio é, ao mesmo tempo, o da representação, do símbolo religioso, da fórmula científica e da forma jurídica, etc. Cada campo de criatividade ideológica tem seu próprio modo de orientação para a realidade e refrata a realidade à sua própria maneira. Cada campo dispõe de sua própria função no conjunto da vida social. É seu caráter semiótico que coloca todos os fenômenos ideológicos sob a mesma definição geral" (p.33).
} 
esses documentos desenvolvem uma atitude científica ao observar e descrever a organização estrutural da língua, mas considerando a imensa variedade de formas expressivas que apresentam relevância funcional nas práticas sociais.

Nas palavras de Schneuwly e Dolz (2004, p.77), as práticas sociais de referência para o ensino-aprendizagem "implicam dimensōes, por vezes, sociais, cognitivas e linguísticas do funcionamento da linguagem numa situação de comunicação particular. Para analisá-las, as interpretações feitas pelos agentes da situação são essenciais". É óbvio que a língua está baseada nas regras de um sistema, e que estas só podem ser identificadas e conceitualizadas a partir das propriedades observáveis dos diversos textos utilizados em uma comunidade. Nesse quadro, o estudo da linguagem vai se desenvolver em duas direções.

De um lado, o estudo do sistema da língua, com ênfase na descrição e classificação, na metalinguagem. Trata-se de um procedimento metodológico interno, abstraindo-se as condições efetivas de produção e os efeitos que essas condições exercem sobre a produção. Nessa primeira direção, seguem os métodos tradicionais do ensino de línguas, dando primazia ao sistema e considerando os textos como uma forma secundária de colocar em funcionamento esse sistema. Independentemente do contexto de utilização, as regras e categorias da língua no limite das estruturas frasais são estudadas como propriedades do sistema. Encontram-se, nessa perspectiva, os estudos gramaticais das abordagens didáticas tradicionais, pautadas na descrição das categorias, funções e relações que entram na construção e na estrutura interna língua (langue) enquanto sistema formal.

De outro lado, o estudo das produções verbais em suas dimensões empíricas de funcionamento, centrando-se na análise da organização e do funcionamento dos textos, em uma perspectiva metodológica externa (ou contextual), considerando as relações de interdependência entre características das situações de produção e dos textos, sem descartar o efeito que os textos exercem sobre seus destinatários. $\mathrm{Na}$ segunda vertente, inscrevem-se as proposições dos documentos oficiais para o ensino de língua portuguesa ao darem ênfase à língua viva, dialógica, em constante movimentação, reflexiva e produtiva. Esse enfoque traduz-se na adoção das práticas de linguagem como ponto central do trabalho pedagógico.

Conforme Bakhtin / Voloshinov (1995[1919]), p. 95), "um método eficaz e correto de ensino prático exige que a forma seja assimilada não no sistema abstrato da língua, isto é, como uma forma sempre idêntica a si mesma, mas na estrutura concreta da enunciação, como um signo flexível e variável”. A ênfase recai na "linguagem como atividade, como prática verbal articulada 
às diferentes formas de ação humana", materializadas em "modalidades de funcionamento dos diferentes gêneros de textos em uso - únicas realidades empiricamente atestáveis das línguas" (BRONCKART, 2003, p.78).

Por conseguinte, conceitos operacionais como o da dêixis, da referenciação, da modalização, da polissemia, da transitividade, da categorização gramatical, da marcação, da gramaticalização, da informatividade, da discursivização, enfim, da textualização podem ser acionados para trabalhar em sala de aula, desde que empiricamente observáveis nos enunciados concretos (gêneros discursivos) e onde apresentam variações e adaptações condicionadas pelas propriedades particulares da língua em uso em uma formação social.

Nessa segunda vertente, encontra-se uma perspectiva de mudança baseada na concepção do ensino de língua materna que assume uma "didática da diversificação” (SCHNEUWLY, 1991), movimento contrário à primeira abordagem que é centrada na unicidade da língua e na qual se enfatiza principalmente uma abordagem puramente gramatical,

destinada a dotar os alunos de uma consciência explícita das principais categorias e estruturas do sistema da língua, pensando-se que, com essa base, os alunos desenvolveriam, posteriormente, uma maestria textual, tanto em relação aos aspectos de produção quanto aos de compreensão-interpretação (BRONCKART, 2003, p. 84).

Portanto, bem distante das perspectivas que visam descrever os fatos em uma abordagem interna, os estudos do segundo tipo tomam como unidade de análise os textos, vistos como "semiotização de ação de linguagem situada, que se efetua tomando um dos modelos de gêneros disponíveis no arquitexto de uma determinada língua natural" (BRONCKART, 2006). Com base na teoria da enunciação bakhtiniana e na teoria da aprendizagem vygotskiana, o autor e demais representantes do chamado Grupo de Genebra buscam uma base teórica para o desenvolvimento (e funcionamento) da linguagem de cunho sóciointeracionista ${ }^{3}$ que possa ser utilizada com finalidades didáticas (SCHNEUWLY, 2004; BRONCKART, 2003; 2006).

\footnotetext{
${ }^{3}$ Como salienta Machado (2007), o interacionismo sociodiscursivo é uma vertente da psicologia da linguagem que se articula, em uma relação dialética, com a didática de línguas. É justamente por ser um campo interdisciplinar que seus postulados são facilmente reduzidos; o que pode facilitar "uma interpretação que toma o todo pela parte", como sugere a autora.
} 
É, nesse contexto, que o conceito de gênero discursivo vai permitir uma articulação entre as práticas sociais e os objetos escolares (SCHNEUWLY; DOLZ, 2004). Dessa forma, ganha impulso a tese de que o estudo da língua recobraria mais consistência e relevância se elegesse como ponto de referência o texto como "entidade genérica" em relação de interdependência com o contexto no qual é produzido, isto é, cada texto apresenta mecanismos de textualização e enunciativos que lhe assegurem a coerência interna de acordo com as suas condições de produção.

O contraste com a primeira abordagem pode ser sintetizado nesse ponto: quais têm sido os ganhos de um viés didático que isola as frases articuladas na superfície textual (e isso quando o professor as focaliza no texto e não se restringe às frases, soltas, isoladas)? Nesse quadro, os investimentos em formação contínua de professores de LP evidenciam, cada vez mais, a urgência da mudança de perspectiva que amplie a concepção de língua, de gramática, de texto e de objeto de ensino.

Nas abordagens "tradicionais", ainda que nos últimos anos o enfoque nos textos se torne cada vez mais presente, buscam-se nelas categorias gramaticais e o funcionamento de estruturas sintáticas, ou seja, continua ausente o estudo das regularidades textuais, o estudo das regras sociais de como os textos são produzidos e interpretados, a reflexão sobre para que servem e o que as pessoas fazem com eles no cotidiano das práticas sociais. Chega-se ao texto, não enquanto materialização da ação de linguagem; consequentemente, não se vai ao uso da língua e às implicações da textualidade. Também não se abordam as práticas discursivas, nem a compreensão dos processos pelos quais um sujeito realiza dentro delas para a reprodução / perpetuação / transformação das práticas em uma situação social.

Todavia, para que isso aconteça, é preciso ir além dos elementos linguísticos do texto e considerar os extralinguísticos, ou seja, as condições que ensejaram a sua produção enquanto enunciado; os fatores pragmáticos envolvidos que lhe deram sustentação e condições para a concretização discursiva, dando-lhes identidade e funcionalidade - o que se apresenta em estreita relação com os pressupostos da perspectiva funcional dos estudos linguísticos. 


\section{O trabalho pedagógico com LP a partir de uma concepção de gramática funcional}

Nas atividades de ensino-aprendizagem de língua, constantemente ouvimos falar da importância de uma visão de ensino de língua materna que seja capaz de provocar um deslocamento que implique a mudança de enfoque: da língua (gramática) para o uso da linguagem em processos comunicativos.

Na década de 80, começava a ecoar a voz de Geraldi (1984) que, inserido na "virada pragmática ou comunicativa", propunha "o texto em sala de aula" e não a gramática, como a principal unidade de trabalho do professor de Língua Portuguesa. No Brasil, entretanto, o texto ganhava o estatuto de principal unidade de ensino, mas não ainda de objeto de ensino. Os professores da educação básica participavam dessa mudança de atitude em relação à "gramática descontextualizada" e adotava o "texto como pretexto para estudar gramática". $\mathrm{O}$ debate se tornaria cada vez mais acirrado nos anos seguintes, mas os conteúdos das aulas voltados para a gramática normativa, para as classes de palavras e suas flexões, para as estruturas sintáticas das frases continuaram e (ainda continuam) resistindo fortemente.

Nesta última década, há consenso quanto à importância do ensino de gramática ${ }^{4}$ no processo de conhecimento e uso da língua materna. Contudo, pairam dúvidas entre os professores da educação básica sobre "o que ensinar", "como ensinar", "com quais ferramentas didáticas ensinar" e de "como trabalhar a gramática em sala de aula" para que ela seja de fato um saber significativo para o aluno.

Aparício (2006) e Silva (2010) apresentam estudos relevantes, demonstrando a necessidade de renovação do ensino de gramática enquanto atividade linguística que produza efeitos no processo interlocutivo. Nesse

\footnotetext{
${ }^{4}$ Surgem esforços para a implementação de Diretrizes Curriculares, que antes eram de exclusiva atribuição do MEC e que agora passam a ser um direito-dever de estados e municípios. O propósito dessa descentralização dos documentos oficiais (do MEC para as secretarias de educação estaduais e municipais) tem sido o de fornecer parâmetros e diretrizes para o ensino de LP, com o objetivo de implantar uma profunda modificação na concepção de linguagem, de objeto e de ensino da língua materna, ainda que o quadro teórico e epistemológico de tais diretrizes continue fundamentado nos PCN, como fonte principal de referência.
} 
quadro, surge o conceito de "prática de análise linguística", 5 que, segundo Aparício (2006), foi cunhado por Geraldi no texto Unidades básicas do ensino de português, de 1981 e amplamente divulgado no livro-coletânea $O$ texto na sala de aula, de 1984. Silva (2010) demonstra a repercussão do termo proposto pelo autor ao afirmar que os PCN adotam a nomenclatura análise linguística para se referir a práticas de ensino / aprendizagem com a língua em uso, evitando utilizar o termo como sinônimo de ensino de gramática. Nessa perspectiva, estudos sobre o tratamento didático que os conteúdos gramaticais recebiam passaram a ser discutidos e reavaliados.

Pesquisadores como Castilho (1998) e Travaglia (1996) propõem que as "aulas de gramática" configurem um conjunto de "atividades de análise e reflexão sobre a língua" como suporte e subsídio, perpassando atividades pedagógicas com leitura, produção e oralidade. O objetivo do ensino na disciplina de Língua Portuguesa passa, então, a ser o conhecimento linguísticodiscursivo, especialmente, advindo das práticas sociais materializadas pelos usuários da língua num determinado contexto.

Dessa forma, os documentos oficiais alertam para o planejamento de atividades que recriem na sala de aula as situações enunciativas vividas fora do ambiente escolar, em que a escola funcione como um "lugar" para a transformação das práticas de linguagem situadas extraescolares para intraescolares, via transposição didática.

Assim, os documentos oficiais não recomendam o ensino gramatical desvinculado das práticas de linguagem em sua dimensão histórica, mas preconizam a necessidade de análise e sistematização dos elementos linguísticos decorrentes de tais práticas. Como amplamente divulgado por eles, as atividades de ensino-aprendizagem devem focar o uso e a reflexão, o que é salientado na passagem a seguir que, a nosso ver, constitui um autêntico "tratado" daquilo que não se pode fazer:

o uso do texto como expediente para ensinar valores morais e como pretexto para o tratamento de aspectos gramaticais; a excessiva valorização da gramática normativa e a insistência nas regras de exceção,

\footnotetext{
${ }^{5}$ Não desconhecemos a trajetória do termo "análise gramatical”, associada às atividades epilinguísticas e metalinguísticas, da Proposta Curricular para o Ensino de Língua Portuguesa (PCLP), desenvolvidas no trabalho de Aparício (2006); mas, em razão dos objetivos deste trabalho, circunscrevemo-nos às pesquisas efetivadas a partir dos PCN.
} 
com o consequente preconceito contra as formas de oralidade e as variedades não-padrão; o ensino descontextualizado da metalinguagem, normalmente associado a exercícios mecânicos de identificação de fragmentos linguísticos em frases soltas; a apresentação de uma teoria gramatical inconsistente -uma espécie de gramática tradicional mitigante e facilitada" (BRASIL, 1998, p. 18).

Nada é suficiente para explicitar o que vem a ser esse movimento de renovação atrelado às práticas discursivas como conteúdo estruturante para as práticas com a leitura, a produção oral e escrita e a análise linguística. Professores ainda buscam respostas para velhas questões: "continuamos com o estudo da gramática como um fim em si mesmo"?; "continuamos com o "normativismo" para respaldar o julgamento dos usos que não estão de acordo com aquilo que está prescrito na gramática normativa"?; são questôes antigas rondando os professores, e que demonstram que ainda se encontram emaranhados na discussão sobre o objeto da ciência linguística, embora os PCN tenham explicitado que "o ensino de LP deve se dar num espaço em que as práticas de uso da linguagem sejam compreendidas em sua dimensão histórica e social". (BRASIL, 1998, p. 34-destaque nosso).

Diante do desafio que se apresenta ao professor, qual o lugar dos componentes gramaticais? Como fazer a articulação entre gramática, texto e gênero de discurso nas atividades didáticas? $\mathrm{Na}$ busca de respostas, têm-se conduzido reflexões ${ }^{6}$ partindo de um pressuposto epistemológico comum: a linguagem numa concepção sociointeracionista, vista como lugar de interação humana, de interlocução, em elaboração sócio-histórico-cultural constante pelo sujeito na sua relação com seus interlocutores por meio de textos.

A escola tem uma tarefa relacionada à "adequação social do produto linguístico de seus alunos" (NEVES, 2000, p. 52), significando que as atividades de ensino-aprendizagem de LP devem centrar-se nas práticas de

\footnotetext{
${ }^{6}$ Reunidos durante atividades do projeto de pesquisa "Gêneros Textuais e Ferramentas Didáticas para o Ensino-Aprendizagem de Língua Portuguesa”, realizadas na Universidade Estadual de Londrina, os autores deste texto têm partido da premissa básica de que as mediações formativas se constituem de práticas letradas específicas, orientadas para a interação social e para as atividades de linguagem que as configuram, assim como para a apropriação de saberes sobre a língua e seu funcionamento.
} 
linguagem em funcionamento na gramática funcional. ${ }^{7}$ A autora defende a postura "funcionalista" ${ }^{8}$ citando um conjunto de diretrizes entre as quais dá destaque para:

i) o caráter não-discreto das categorias; (ii) fluidez semântica, com valorização do papel do contexto; (iii) gradualidade das mudanças e coexistência de etapas; (iv) regularização, idiomatização e convencionalização contínuas (NEVES, 2006, p. 15).

Os postulados da pesquisadora sintetizam os fundamentos de base da gramática funcional e têm contribuído para explicitar as reflexões na perspectiva em que se encontra a segunda orientação dos estudos da língua. Desse quadro, convém conduzir a argumentação em defesa das seguintes teses, considerando que: 1) os textos apresentam diferentes níveis de apreensão; 2) as análises linguísticas de orientação funcionalista ${ }^{9}$ assumem como premissa fundamental a língua como estrutura maleável, sujeita às pressões do uso e constituída de um código não totalmente arbitrário; 3) alguns fenômenos linguísticos são resultantes da adaptação da estrutura gramatical às necessidades comunicativas dos usuários da língua - marcando o estilo de um sujeito singular em um evento discursivo irrepetível no tempo e no espaço. A partir disso, podemos concluir que a abordagem funcionalista coincide com a teoria da enunciação bakhtiniana - o alicerce epistemológico dos PCN - e com ele, a noção de enunciado concreto relativamente estável.

\footnotetext{
${ }^{7}$ Segundo Neves (1997, p.16), a gramática de usos é uma gramática funcional e "colocar a língua em uso é ter presente que o uso da linguagem e a produção de texto se fazem na interação".

${ }^{8}$ Conforme Neves (2004, p. 1), "caracterizar o funcionalismo é uma tarefa difícil, já que os rótulos que se conferem aos estudos ditos "funcionalistas" mais representativos geralmente se ligam diretamente aos nomes dos estudiosos que os desenvolveram, não a características definidoras da corrente teórica em que eles se colocam. A autora se posiciona no sentido de que provavelmente existem tantas versōes do funcionalismo quanto linguistas que se chamam funcionalistas, denominação que abrange desde os que simplesmente rejeitaram o formalismo até os que criam uma teoria. A verdade é que, dentro do que vem sendo denominado - ou autodenominado - "funcionalismo", existem modelos muito diferentes".

${ }^{9}$ Os linguistas da vertente funcionalista buscam explicar as formas da língua a partir das funçóes que elas desempenham na interação.
} 
Para os sociointeracionistas, os usos concretizados da língua nas práticas sociais são marcados pela historicidade (porque não são criados no momento da fala), são formas culturais que estão lá, nas atividades dos predecessores, já existiam antes, não são "modelos estanques nem estruturas rígidas, porque são formas culturais e cognitivas de ação social corporificadas na linguagem" (MARCUSCHI, 2008, p.157). As múltiplas "espécies de textos" que circulam em um grupo social põem à mostra as características do modelo social enquanto construto sócio-histórico, mas também apresentam as marcas resultantes da adaptação de um agente-produtor individual em um contexto singular. E por sofrerem coerções de toda ordem - pois são entidades dinâmicas e fluidas -, a rigidez das normas e regras das descriçõos gramaticais tradicionais não podem ser condizentes com essa força de transformação.

Diante dessa constatação, o professor precisa estar preparado para tratar usos singulares, emergentes dos parâmetros de representação do contexto de produção, responsáveis pela adaptação, transformação ou hibridismo de um gênero na forma como se materializa em uma produção situada.

Para além do sistema, estão os aspectos funcionais, situacionais, contextuais (comunicacionais) do uso da língua - preocupações dos estudiosos funcionalistas e dos sociointeracionistas que consideram o texto como unidade empírica / material da análise e o gênero de discurso como o objeto de análise e de ensino. Em conformidade com a abordagem funcionalista e sociointeracionista, aliadas aos preceitos dos PCN, os autores têm se posicionado no sentido de que a escola deve abrir suas portas para a diversidade de práticas discursivas, concretizadas no maior número possível de gêneros, de variedades de língua (urbanas / rurais, orais / escritas, formais / informais, cultas / não-cultas e em diferentes mídias de circulação (imprensa, eletrônica e digital).

\section{O Funcionalismo nos documentos oficiais}

Os PCN, as DCE e a PCLP apresentam-se de forma hegemônica no que diz respeito à ênfase à língua viva, dialógica, em constante movimentação, reflexiva e produtiva. Tal ênfase traduz-se na adoção das práticas discursivas como conteúdo estruturante para o ensino, o que, de acordo com Bakhtin / Volochinov (1995[1919], p.108), além "do ponto de vista do deciframento de uma língua morta e do seu ensino", criticam as abordagens que tomam o sistema como base para a compreensão e explicação dos fatos linguísticos "enquanto fatos vivos e em evolução". 
Os estudos linguísticos apregoam, mais especificamente a partir da publicação dos $\mathrm{PCN}$, que a análise linguística não pode ficar reduzida ao trabalho sistemático da gramática. Tais documentos advogam que "aprender a pensar e falar sobre a própria linguagem supõe o planejamento de situações didáticas que possibilitem a reflexão" (p.27). Sobretudo, essa natureza de que falam significa atrelá-la aos recursos expressivos utilizados pelo autor, num determinado gênero, numa determinada situação de comunicação (SCHNEUWLY; DOLZ, 2004).

Embora os PCN sejam permeados por uma variedade de correntes linguísticas, dentre elas, a abordagem descritiva, a gramática internalizada (ou implícita) $;{ }^{10}$ a abordagem funcional é o foco de análise no presente texto. Silva (2010, p.40) afirma que, a despeito da variedade de correntes linguísticas do documento, este não deixa dúvidas sobre a concepção de gramática refutada. Para o autor, a insistência nesse posicionamento é tão forte que, muitas vezes, quando explicitam determinados aspectos a serem trabalhados, salientam mais o posicionamento teórico não defendido que o assumido.

$\mathrm{O}$ referido autor ${ }^{11}$ enfoca que as propostas de ensino de gramática nos $\mathrm{PCN}^{12}$ são uma mistura de abordagens teóricas, com enfoque descritivo de cunho funcional, perpassando implicitamente a sua proposta. Além disso, preconizam que, no eixo da reflexão, o docente deve planejar situações didáticas "que possibilitem a análise não apenas sobre os diferentes recursos utilizados pelo autor do texto, mas também sobre a forma pela qual a seleção de tais recursos reflete as condições de produção" (op. cit., p.28).

Este uso funcional é reiterado em diversas partes do documento, sempre chamando a atenção para a regularidade dos gêneros e sua relação contextual e os processos anafóricos, marcadores temporais / lógicos / argumentativos / dêiticos, etc. ${ }^{13}$ Tal vertente dos estudos linguísticos pode ser percebida, entre outros trechos, no fragmento a seguir:

\footnotetext{
${ }^{10}$ Para mais aprofundamento na questão, ver Silva (2010).

11 Silva (2010) destaca ainda que o próprio gênero "proposta curricular" motiva a busca de orientações em epistemologias distintas.

${ }^{12}$ Nessa passagem dos PCN, evidencia-se o viés funcional da linguagem, isto é, dos usos para a reflexão, do sistema linguístico influenciado pelos contextos social e cultural. Ainda de acordo com o autor (op. cit., p. 60), o trabalho com os usos linguísticos sugerido por esse prescritor ocorre em função das tipologias tradicionais que são constitutivas dos gêneros.

${ }^{13}$ Ver páginas 52, 60 e 61 dos PCN, como exemplos.
} 
(...) ainda que a unidade de trabalho seja o texto, é necessário que se possa dispor tanto de uma descrição dos elementos regulares e constitutivos do gênero quanto das particularidades do texto selecionado, dado que a intervenção precisa ser orientada por esses aspectos discretizados. A discretização de conteúdos, ainda que possa provocar maior distanciamento entre aspecto tematizado e a totalidade do texto, possibilita a ampliação e a apropriação dos recursos expressivos e dos procedimentos de compreensão, interpretação e produção dos textos, bem como de instrumentos de análise linguística. (BRASIL, p. 48).

A longa citação anterior, ao falar de discretização,${ }^{14}$ sugere que o tratamento a ser dado à reflexão sobre a língua seja por meio das regularidades dos gêneros. Em acordo com os PCN, acreditamos que, quando o docente conhece o gênero com que irá trabalhar, em seus aspectos contextuais, discursivos e linguístico-discursivos, poderá intervir eficazmente na produção de texto (oral ou escrito) de seu aluno. Dessa maneira, é imprescindível, em consonância com o enfoque funcionalista da linguagem, a construção de modelo didático para que ocorra a transposição didática de gêneros para a sala de aula.

\section{A articulação da abordagem funcionalista ao estudo de um gênero de discurso}

De acordo com os pesquisadores do Grupo de Genebra, para que o processo de transposição didática de um gênero se torne viável, é preciso, primeiramente, a elaboração de uma ferramenta mediadora do conhecimento dizível nesse gênero, denominada pelos autores genebrinos de modelo didático do gênero (cf. CRISTOVÃO, 2001; CRISTOVÂO; NASCIMENTO, 2004).

Um modelo didático deve implicar, segundo Bronckart (2003), a análise de um conjunto de textos (considerados do mesmo gênero), tendo como base as representações do contexto de produção e as três camadas do que o autor denomina de folhado textual: a infraestrutura geral do texto, os mecanismos de textualização e os mecanismos enunciativos. Para o autor, esses elementos

\footnotetext{
${ }^{14} \mathrm{O}$ termo discretização é definido em nota de rodapé nos seguintes termos: "por discretização, compreende-se a identificação dos diversos aspectos que devem ser investidos nos conhecimentos pelos quais se opera nas práticas de linguagem, de modo a priorizar o tratamento de um ou de outro deles nas atividades didáticas" (BRASIL, p.36).
} 
de análise conseguem abranger os três níveis de capacidades de linguagem envolvidas na produção de um gênero, a saber, capacidades de ação, capacidades discursivas e capacidades linguístico-discursivas. Dessa forma, por exemplo, se há frequência acentuada de organizadores lógico-discursivos em determinado gênero, como o artigo opinativo, e os estudantes têm relativa dificuldade em seu uso, o professor deve partir deles para que seja feita uma reflexão dos elementos linguísticos-discursivos para realizar, em seguida, atividades de ensino / aprendizagem de leitura e produção textual.Esses modelos devem ser funcionais, descritivos e facilitadores da apreensão do todo complexo que é um gênero. Além disso, permitem a visualização do panorama das capacidades de linguagem a serem desenvolvidas. Para efeito de exemplificação, trazemos a seguir uma síntese do procedimento metodológico que culmina com o que denominamos modelo didático de um gênero.

Em atividades de formação, temos enfocado a heterogeneidade de usos, implementado entre os professores em pré-serviço e em serviço, a importância da construção do modelo que possa dar subsídios à elaboração do planejamento didático sobre o gênero a ser efetivamente ensinado de acordo com as capacidades dos alunos. De acordo com Schneuwly e Dolz (2004), o modelo didático do gênero vai culminar na produção de uma sequência didática (doravante SD). Os autores assim definem o procedimento SD: “é um conjunto de atividades escolares organizadas, de maneira sistemática, em torno de um gênero textual oral ou escrito" (DOLZ; NOVERRAZ; SCHNEUWLY, 2004, p.97). Ela tem a finalidade de ajudar o estudante a dominar um gênero de texto, permitindo-lhe adequar o seu discurso a uma determinada situação de comunicação.

Evidentemente, precisamos levar para a instituição escolar os gêneros que eles não dominam ou dominam minimamente. Para isso, acreditamos que, com essa ferramenta, seja possível criar contextos eficazes de comunicação, a partir de propostas variadas de leitura, escrita, oralidade e escuta, todas perpassadas por atividades de análise linguística.

\section{Uma proposta de trabalho}

Para exemplificar de que forma poderíamos desenvolver um trabalho com gênero discursivo em uma perspectiva funcional, apresentamos uma síntese da análise textual de um corpus retirado do Guia para fazer o bem, na revista Veja, Edição Especial, dezembro de 2001, do ano 34, n. ${ }^{\circ} 51$ (disponível para o leitor em: <www.veja.com.br/acervodigital/home.asp>). Esse guia, 
publicado pela revista Veja-semanário de mídia impressa brasileira de grande circulação nacional-, foi apresentado em forma de Edição Especial, isto é, como uma publicação não periódica anexa a uma determinada edição da revista. O seu conteúdo temático tratava de questôes de responsabilidade social. Nessa edição, havia reportagens relatando as ações realizadas por organizações não governamentais (ONGs), instituições e fundações filantrópicas, abordando as vantagens que as corporações têm quando investem em projetos voltados para a comunidade, e havia também propagandas institucionais, que informavam sobre quais projetos têm sido desenvolvidos por determinadas empresas que têm compromisso com causas de responsabilidade social. Como corpus de nossa pesquisa, escolhemos cinco peças publicitárias que se configuram no gênero "propaganda institucional". Os exemplares desse gênero se caracterizam por lançarem mão de uma série de sistemas de linguagem, como o verbal e o visual (figuras de expressão e recursos plásticos - cor, layout, formato das letras, tipo de papel, etc.), isto é, exemplares de um gênero "multissemiótico" - constituídos de mais de uma semiótica (sistema de linguagem)-, assim como de elementos "sincréticos", ${ }^{15}$ que possibilitam a realização de uma leitura integrada do texto verbal (materialidade linguística) e do não-verbal (materialidade visual), ou seja, a apreensão do sentido textual só se dá pela "estratégia global de comunicação" (FLOCH 1988, 1995 apud SAITO 2007; 2009), uma vez que o sentido é construído a partir do imbricamento dessas diferentes materialidades - a sua semiose. Sabemos que o processamento textual desse gênero só pode ocorrer a partir dessa leitura global; porém, como nesta pesquisa o foco está na apresentação de uma proposta de análise linguística conforme propõe o Funcionalismo, deixaremos a materialidade não-verbal para ser trabalhada em um outro momento.

\footnotetext{
${ }^{15}$ Segundo Saito (2009; 2007), Floch empenhou-se em precisar a noção de sincretismo e estabelecer propostas de abordagem para os textos sincréticos. Da contribuição de suas pesquisas, os textos sincréticos passaram a ser vistos como sendo aqueles em que uma pluralidade de substâncias (por exemplo, sonora, visual, plástica) do plano da expressão possibilita a manifestação de uma forma única de linguagem (no sentido de estrutura significante). Apresentam-se, portanto, os textos sincréticos como unidades de sentido, ainda que suas estruturas significantes sejam compostas por uma pluralidade de linguagens e independentemente da diversidade de substâncias das quais se vale a manifestação. $\mathrm{O}$ sincretismo é considerado uma estratégia global de comunicação que "administra" o processo de textualização de diferentes linguagens, vertendo-as em um contínuo discursivo único de apreensão verbal.
} 


\section{O estudo da materialidade verbal do gênero "propaganda institucional sua planificação textual"}

De acordo com Pinho (1990), há uma distinção entre propaganda institucional e social. $\mathrm{O}$ autor compreende a institucional como sendo aquela que "tem como objetivo principal posicionar empresas, tanto para o público interno como para o público externo, não visando diretamente conceituar um produto ou serviço", Sendo assim, podemos concluir que, mesmo estando no suporte ${ }^{16}$ Guia para fazer o bem, esse gênero tem um propósito comunicativo específico, que contribui para que a construção textual por parte do agenteprodutor seja diferente. As estratégias discursivas elaboradas por ele, tanto na materialidade verbal quanto na não-verbal têm uma característica própria, isto é, serão postos valores em discurso nas diferentes semióticas. O gênero "propaganda institucional" apresenta propriedades singulares que definem o seu estilo, composição e tema. $\mathrm{O}$ intuito discursivo do agente-produtor desse enunciado é falar ao público (destinatário) sobre uma organização comercial, de modo que as pessoas adquiram confiança nela e se disponham a uma atitude mais favorável em face de seus produtos e serviços, o que não deixa de ser uma estratégia de marketing social. Assim, observamos nas cinco propagandas que analisamos: 1) Nestlé; 2) Bradesco; 3) Credicard; 4) Serasa; 5) Ethos - as características da sua organização interna para, em um segundo momento, refletirmos sobre o seu uso pelos agentes-produtores, tendo em vista as condições de produçãoo (as representações do mundo físico e sociossubjetivo), assim como os efeitos de sentido que buscariam provocar nos destinatários.

\section{A infraestrutura do gênero anúncio publicitário institucional}

Com o objetivo de perceber as características da organização interna que diferenciam esse gênero de outros e definir a relação que o enunciador instaura com a situação de produção de seu texto (aqui implicados o agente produtor, o destinatário, o veículo de circulação, o jogo de representações de uns sobre os outros, etc.) são aplicados aos textos uma "grade de análise" (GONÇALVES, 2007; 2009) para a observação de certos aspectos linguístico-discursivos.

\footnotetext{
${ }^{16}$ Estamos entendendo suporte como faz Marcushi (2008), "como um lócus físico ou virtual com formato específico que serve de base ou ambiente de fixação do gênero materializado como texto" (MARCUSCHI, 2008, p.174).
} 
Dessa maneira, pudemos reconhecer as categorias gramaticais e lexicais que nos permitiram inferir quais seriam as regularidades dos textos do gênero propaganda institucional, isto é, quais são as propriedades linguísticodiscursivas específicas da textualidade que estão articuladas ao exame das condiçôes externas de produção de cada uma e que lhes asseguram a coerência global: a planificação, os segmentos que o constituem (tipos de discurso), os mecanismos de textualização (coesão nominal e verbal), a expressão das modalizações, a seleção lexical, etc.

Com os limites de uma síntese, serão apresentados dados que darão subsídio à descrição dos vários níveis de funcionamento dos textos do gênero em foco. Em relação ao contexto de produção, isto é, o conjunto de parâmetros que podem influenciar a forma como o texto é organizado (lugar de produção, momento da produção, papel da interação, etc.), a TAB. 1 apresentada a seguir atesta as unidades linguísticas que, nos textos em análise, demonstram a implicação dos parâmetros da ação de linguagem ${ }^{17}$ em curso.

TABELA 1

A implicação do contexto de produção

\begin{tabular}{|c|c|c|c|c|c|c|c|c|}
\hline \multirow[b]{2}{*}{$\begin{array}{l}\text { Enuncia- } \\
\text { dores }\end{array}$} & \multirow[b]{2}{*}{$\begin{array}{l}\text { Pronome } \\
\text { da } 1^{a} \\
\text { pessoa do } \\
\text { singular }\end{array}$} & \multirow[b]{2}{*}{\begin{tabular}{|l|} 
Pronome \\
da $1^{\mathrm{a}}$ \\
pessoa \\
plural e \\
formas \\
verbais \\
correspon- \\
dentes
\end{tabular}} & \multirow{2}{*}{$\begin{array}{l}\text { Pronome } \\
\text { da } 2^{\mathrm{a}} \\
\text { pessoa do } \\
\text { singular }\end{array}$} & \multirow{2}{*}{$\begin{array}{l}\text { Pronome } \\
\text { da } 3^{\mathrm{a}} \\
\text { pessoa do } \\
\text { singular e } \\
\text { do plural }\end{array}$} & \multirow{2}{*}{$\begin{array}{l}\text { Dêitico } \\
\text { temporal } \\
\text { e/ou } \\
\text { espacial }\end{array}$} & \multicolumn{3}{|c|}{ Frases não-declarativas } \\
\hline & & & & & & $\begin{array}{l}\text { Frase } \\
\text { inter- } \\
\text { rogativa }\end{array}$ & $\begin{array}{l}\text { Frase } \\
\text { excla- } \\
\text { mativa }\end{array}$ & $\begin{array}{l}\text { Frase } \\
\text { impe- } \\
\text { rativa }\end{array}$ \\
\hline 1. Nestlé & & 0 & 0 & 10 & 0 & 0 & 0 & 0 \\
\hline 2. Bradesco & 10 & 0 & 0 & 1 & 0 & 0 & 0 & 0 \\
\hline 3. Credicard & & 0 & 0 & 16 & 0 & 0 & 0 & 0 \\
\hline 4. Serasa & & 0 & 0 & 9 & 2 & 0 & 0 & 9 \\
\hline 5. Ethos & & 0 & 0 & 4 & 0 & 0 & 0 & 2 \\
\hline
\end{tabular}

Os resultados evidenciam, nas propagandas institucionais em análise, o uso do pronome de terceira pessoa do singular / plural em todos os textos analisados, denotando um expor, isto é, o conteúdo temático é "interpretado

\footnotetext{
${ }^{17}$ Segundo Bronckart (2003, p.99), "a ação de linguagem reúne e integra os parâmetros do contexto de produção e do conteúdo temático, tais como um determinado agente os mobiliza, quando empreende uma intervenção verbal".
} 
sempre à luz dos critérios de validade do mundo ordinário" (BRONCKART, 2003, p.154) e o uso de frases imperativas demonstra a tendência pela utilização do discurso interativo implicando ${ }^{18}$ o destinatário, em um efeito de sentido de proximidade e intimidade. Apenas no anúncio do Bradesco ocorreu a 1. ${ }^{\text {a }}$ pessoa do singular com valor exofórico, fato que pode ser correlacionado à não-identificação do enunciador enquanto indivíduo uno, mas como um sujeito que deseja ser reconhecido na pluralidade de um "nós" que irmana, reúne todos aqueles que conhecem os perigos que a ameaça representa (cientistas, médicos, empresários, administradores públicos, etc.) e que agem pelo bem comum - lutam pela saúde das pessoas, pela preservaçáo do meio ambiente etc.

A ausência de frases interrogativas e exclamativas atesta que a intenção dos agentes-produtores é convencer pela exposição de um fato divulgado por um agente legitimado pela empresa / instituição da qual é porta-voz, o qual consegue provar o que diz fazer e explicitar as razóes que o levam a isso. Tal ausência deve-se, sobretudo, ao fato de que não temos turnos de fala, mas uma interação verbal encenada (BRONCKART, 2003).

Em relação ao ato de produção, os textos apresentam um expor implicado, ou seja, um discurso interativo situado no próprio ato de produção, uma vez que as representaçóes construídas pelos agentes produtores envolvem a concepção de uma produção de texto em que os referentes desejáveis são o conteúdo temático do texto (um problema social que afeta a todos os cidadãos), as informações científicas sobre a gravidade do problema, o envolvimento da empresa / instituição sobre o seu interesse pelo bem-estar das pessoas.

Na TAB. 2, é apresentado um levantamento dos tempos verbais utilizados na construção textual.

\footnotetext{
${ }^{18}$ Quando o discurso é implicado, o agente-produtor deixa-se mostrar por meio de dêiticos de tempo, espaço e pessoa.
} 
TABELA 2

Unidades que indicam a conjunção ou a disjunção ${ }^{19}$ do mundo discursivo

\begin{tabular}{l|c|c|c|c|c}
\hline Enunciador & $\begin{array}{c}\text { Presente do } \\
\text { Indicativo }\end{array}$ & $\begin{array}{c}\text { Pretérito } \\
\text { Perfeito simples } \\
\text { ou composto }\end{array}$ & $\begin{array}{c}\text { Pretérito } \\
\text { Imperfeito } \\
\text { Simples }\end{array}$ & $\begin{array}{c}\text { Pretérito }+ \\
\text { que Perfeito } \\
\text { composto }\end{array}$ & $\begin{array}{c}\text { Futuro simples } \\
\text { ou perifrástico } \\
\text { com auxiliar } \underline{\text { r }}\end{array}$ \\
\hline 1. Nestlé & 7 & 4 & 0 & 0 & 0 \\
2. Bradesco & 11 & 0 & 0 & 0 & 0 \\
3. Credicard & 10 & 2 & 0 & 1 & 0 \\
4. Serasa & 8 & 0 & 0 & 0 & 0 \\
5. Ethos & 7 & 1 & 1 & 0 & 0 \\
\hline
\end{tabular}

O tempo predominante é o presente do indicativo. O pretérito perfeito e o imperfeito aparecem em apenas $20 \%$ dos textos. A absoluta utilização do presente do indicativo que $100 \%$ dos anúncios de campanha institucional são construídos por segmentos de discurso interativo (cf. BRONCKART, 2003), ou seja, por segmentos nos quais se constrói um mundo discursivo conjunto ao da situação de produção. Para Machado (2005, p.243), é "nesse tipo de discurso que se marca uma relação mais estreita entre o mundo discursivo e $o$ mundo da situação concreta de produção". A exploração do presente do indicativo e pelo pretérito (simples ou composto no português) exprimem a relação estabelecida entre o momento dos acontecimentos verbalizados no texto e o momento da tomada da palavra da interação (BRONCKART, 2003, p.168). Há também nos anúncios relativa frequência dos verbos no imperativo (olhe, pense, repare, junte), formas nominais no infinitivo e no gerúndio (contar crescendo, colocando, contar, etc.), além de locuções verbais em que as formas nominais aparecem como segundo elemento. Em relação aos verbos no imperativo, como já dito, eles têm o objetivo de "ganhar o interlocutor"; em se tratando das formas nominais simples ou sob a forma de locuções, estão cumprindo no texto a função de marcar o presente do indicativo. Na cena

\footnotetext{
${ }^{19}$ Quando um texto deixa claras as instâncias do agente produtor com os parâmetros materiais da ação de linguagem (produtor, interlocutor e sua situação no tempo e no espaço), dizemos que o texto IMPLICA os parâmetros com elementos dêiticos integrados ao tema e, para interpretar, na íntegra, essa produção empírica, é necessário ter acesso às condições de produção, contextualmente falando. Se, por outro lado, tal relação não é explicitada e "as instâncias de agentividade do texto mantêm uma relação de interdependência ou indiferença em relação aos parâmetros da ação de linguagem em curso" (BRONCKART, 2003, p. 154), dizemos que o texto possui AUTONOMIA.
} 
enunciativa definida por esses anúncios, é a voz da instituição ou empresa, textualizada por um agente produtor que se dirige aos destinatários para mostrar e explicar como, por meio das ações por ela engendradas, consegue "fazer o bem" à sociedade.

\section{A organização sequencial e os planos de texto}

Em relação ao modo como se compõem e se encadeiam as sequências de enunciados, nesse gênero, predominam explicações e argumentações. Apesar da grande heterogeneidade tipológica de sequências (ADAM, 1990), ou seja, de tipos textuais (MARCUSCHI, 2008), observa-se uma planificação dos textos que vem da forma de organização do tipo de discurso dominante para expor informações.

O objetivo precípuo da sequência argumentativa é o de mostrar os processos da lógica, do pensamento, do raciocínio. $\mathrm{O}$ agente produtor utilizase da sequência argumentativa toda vez que prevê um discurso passível de contestação, controversa (cf. Nestlé, Bradesco, Credicard, Serasa e Instituto Ethos). A sequência explicativa, diferentemente da argumentativa, tem origem na confirmação de um objeto de estudo incontestável. Entretanto, seja um acontecimento natural ou uma ação humana, tais fenômenos configuram-se incompletos, necessitando de um desenvolvimento que servirá para responder a questôes ou a contradições aparentes. Dito de outro modo, às vezes, devido ao hermetismo de um objeto, devemos apresentar as causas de uma afirmação inicial e esclarecer as polêmicas possíveis.

Como nesses anúncios predomina um discurso do eixo do expor do tipo interativo, eles se apresentam sob a forma de plano expositivo, uma vez que essa é a forma de organização típica desse tipo de discurso, o que pode ser visualizado a seguir:

TABELA 3

Total de ocorrências dos tipos de sequência nos anúncios

\begin{tabular}{l|c|c|c|c|c|c|c}
\hline No DE & \multicolumn{7}{|c}{ TIPOS DE SEQUÊNCIAS } \\
\hline TEXTOS & injuntiva & descritiva & argumentativa & dialogal & narrativa & Explicativa & esquematizações \\
\hline 05 & 2 & 1 & 5 & 2 & 0 & 4 & 0 \\
\hline
\end{tabular}

Em relação aos mecanismos de textualização (reagrupados em três conjuntos: a conexão, a coesão nominal e a coesão verbal), os dados são apresentados a seguir. Percebemos que os textos do gênero apresentam um alto 
índice de anáforas nominais por repetição, podendo ser indício de característica do discurso publicitário, no qual o enunciador visa aliar certos conteúdos ao objeto de discurso pela repetição de informações que remetem a ele. As retomadas anafóricas por repetição contribuem para a continuidade temática, assim como para a progressão do conteúdo (CHAROLLES, 1988), conforme ilustradas abaixo:

TABELA 4

As cadeias coesivas

\begin{tabular}{|c|c|c|c|c|c|c|}
\hline \multirow[t]{2}{*}{ Enunciador } & \multirow{2}{*}{$\begin{array}{c}\text { Cadeias } \\
\text { Anafóricas }\end{array}$} & \multirow[t]{2}{*}{$\mathrm{SN}$} & \multirow{2}{*}{$\begin{array}{c}\text { Anáforas } \\
\text { Pronominais }\end{array}$} & \multicolumn{2}{|c|}{ Anáforas Nominais } & \multirow{2}{*}{$\begin{array}{l}\text { Total de } \\
\text { Anáforas } \\
\text { Nominais }\end{array}$} \\
\hline & & & & $\begin{array}{l}\text { Por } \\
\text { Repetição }\end{array}$ & $\begin{array}{l}\text { Por } \\
\text { substituição }\end{array}$ & \\
\hline 1. Nestlé & 6 & 22 & 0 & 4 & 2 & 6 \\
\hline 2. Bradesco & 4 & 8 & 11 & 10 & 0 & 10 \\
\hline 3. Credicard & 3 & 30 & 4 & 11 & 0 & 11 \\
\hline 4. Serasa & - & 22 & 6 & 7 & 0 & 7 \\
\hline 5. Ethos & 7 & 13 & 2 & 3 & 2 & 5 \\
\hline
\end{tabular}

Os anúncios de campanha institucional, como já demonstrado nas tabelas anteriores, apresentam a predominância do discurso da ordem do expor, nos quais predominam os organizadores lógicos (o que não descarta o uso de organizadores de valor temporal ou espacial, comuns no discurso da ordem do narrar). O discurso expositivo voltado à transmissão e construção de saberes que estão em conjunção ao mundo ordinário da ação de produção, fala do mundo no qual o agente produtor age, sem ruptura entre o mundo dito e o mundo da situação. Nesse gênero, os organizadores lógicos predominam, enquanto os temporais e espaciais apresentam baixo índice de ocorrência. Isso pode ser explicado pela alta frequência de sequências explicativas e pela baixa frequência de sequências narrativas na composição textual do gênero, como é apresentado a seguir: 
TABELA 5

Mecanismos de sequenciação

\begin{tabular}{l|c|c|c|c|c|c|c}
\hline & \multicolumn{7}{|c}{ Organizadores Textuais } \\
\hline & $\begin{array}{c}\text { Organizadores } \\
\text { temporais }\end{array}$ & $\begin{array}{c}\text { Tipo de } \\
\text { sequência }\end{array}$ & $\begin{array}{c}\text { Organizadores } \\
\text { lógicos }\end{array}$ & $\begin{array}{c}\text { Tipos de } \\
\text { sequência }\end{array}$ & $\begin{array}{c}\text { Organizadores } \\
\text { espaciais }\end{array}$ & $\begin{array}{c}\text { Tipos de } \\
\text { sequência }\end{array}$ & $\begin{array}{c}\text { Total } \\
\text { 1. Nestlé }\end{array}$ \\
2. Bradesco & 0 & SN & 3 & SN & 0 & - & 7 \\
3. Credicard & 0 & 0 & 0 & - & 0 & - & 0 \\
4. Serasa & 0 & - & 3 & SE & 1 & SD & 4 \\
5. Ethos & 2 & SN & 2 & SE & 0 & - & 3 \\
\hline
\end{tabular}

Em relação aos mecanismos enunciativos (instâncias de enunciação, vozes), origem das avaliaçóes e julgamentos sobre aspectos do conteúdo temático (modalizações) que orientam o destinatário na interpretação do conteúdo temático, o total de textos analisados apresentam unidades de modalização.

\section{E para concluir... quais seriam os elementos gramaticais ensináveis a partir da análise e descrição do funcionamento da língua em uma prática discursiva?}

Nos cursos de formação, destacamos a importância do estudo e da pesquisa sobre os gêneros alvo da elaboração do modelo didático que possa indicar ao professor aquilo que seja adequado ensinar aos seus alunos (NASCIMENTO, 2009). Isso significa que essa construção precisa se sustentar a partir da desconstrução e descrição do gênero.

Salientamos também que o modelo descritivo desse gênero publicitário não pode prescindir da abordagem dos diferentes níveis de análise, implicando, a nosso ver, tanto as dimensões do processamento da materialidade linguística (verbal oral ou escrito) como também as dimensões da materialidade do nãoverbal visual (figuras e elementos plásticos), ou seja, dos aspectos não-verbais que se agregam tanto à escrita quanto à fala, apesar de a intenção não ser a de dar relevo a essa dimensão neste trabalho.

$\mathrm{Na}$ análise de textos desse gênero da esfera publicitária, ainda que com os limites de uma síntese, evidenciaram-se as relações entre os sistemas discursivo, semântico e gramatical articulados à interação agente produtor / texto / leitor em um contexto de produção e de recepção bem determinado pela esfera de comunicação de que emergem. Tal articulação exclui a 
possibilidade de selecionar um deles como o mais ou o menos importante para o estudo do funcionamento do texto, visando ao trabalho didático com as práticas discursivas - eixo estruturante para o ensino de língua portuguesa, conforme o que é preconizado pelos PCN, DCE e PCLP.

Em relação aos conteúdos do ensino-aprendizagem de língua portuguesa, as sequências didáticas com esse gênero, que poderão ser elaboradas a partir desse modelo didático, deverão compreender aspectos linguísticos e discursivos implicados ao discurso da ordem do expor, mobilizando elementos que estão em conjunção ao mundo real da ação de linguagem. Dessa forma, acreditamos poder articular os preceitos funcionalistas sustentadores dos documentos oficiais que parametrizam a prática pedagógica dos professores do Ensino Básico, da rede pública de ensino, ao enfoque das práticas discursivas como eixo estruturante para o ensino de língua portuguesa, aproximando o trabalho que o professor desenvolve em sala de aula - "trabalho realizado" -, com aquilo que preconizam os documentos oficiais - "trabalho prescrito".

\section{Referências bibliográficas}

ADAM, J. -M. Eléments de linguistique textuelle. Liége: Mardaga, 1990.

APARÍCIO, A. S. M. A produção da inovação em aulas de gramática do Ensino Fundamental II da escola pública estadual paulista. 2006. 216 f. Tese (Doutorado em Linguística Aplicada) - Instituto de Estudos da Linguagem, Universidade Estadual de Campinas, Campinas, 2006.

BAKHTIN, M.;VOLOCHINOV, V. N. Marxismo e Filosofia da linguagem. Trad. de Michel Lahud e Yara Frateschi Vieira. São Paulo: Hucitec, 1995 [1929].

BRASIL. Parâmetros Curriculares Nacionais: terceiro e quarto ciclos do Ensino Fundamental - Língua Portuguesa. Brasília: MEC/SEF, 1998. 106p.

BRONCKART, J-P. Atividades de linguagem, textos e discursos: por um interacionismo sócio-discursivo. Trad. Anna Rachel Machado e Péricles Cunha. São Paulo: Educ, 2003. 353p.

BRONCKART, J-P. Atividade de Linguagem, Discurso e Desenvolvimento Humano. Campinas: Mercado de Letras, 2006. 260p.

CASTILHO, A. T. de. A gramaticalização. Estudos Linguísticos e Literários, Salvador, v. 19, p.25-63, 1998.

CHAROLLES, M. Introdução aos problemas da coerência dos textos (abordagem teórica e estudos das práticas pedagógicas). In: GALVES, Charlotte et alii. $O$ Texto: leitura e escrita. Campinas: Pontes, 1988, p. 39-91. 
CRISTOVÃO, V. L. L. Gêneros e ensino de leitura em LE: os modelos didáticos de gêneros na construção e avaliação de material didático. 2001. Tese (Doutorado em Linguística Aplicada e Estudos da Linguagem) - Pontifícia Universidade Católica de São Paulo, São Paulo, 2001.

CRISTOVÃO, V. L. L.; NASCIMENTO, E.L. Modelos didáticos de gêneros: questóes teóricas e aplicadas. In: CRISTÓVÃO, V.L.L.; NASCIMENTO, E.L. (Org.). Gêneros Textuais: Teoria e Prática. Londrina: Moriá, 2004, p. 72-95.

DOLZ, J.; SCHNEUWLY, B. Gêneros e progressão em expressão oral e escrita: elementos para reflexões sobre uma experiência suíça (francófona). In: SCHNEUWLY. B; DOLZ, J. Gêneros Orais e Escritos na Escola. Trad. de Roxane Rojo e Glaís Sales Cordeiro. Campinas: Mercado de Letras, 2004.

DOLZ, J.; NOVERRAZ, M.; SCHNEUWLY, B. Sequências didáticas para o oral e a escrita: apresentação de um procedimento. In: SCHNEUWLY, B.; DOLZ, J. Gêneros orais e escritos na escola. Campinas-SP: Mercado de Letras, 2004. p. 95-128.

FLOCH, J. M. Quelques positions pour una sémiotique visuelle. Le Bulletin, Paris, Groupe de Recherches Sémio-Linguistiques, v. 1, n. 4-5, p. 1-16, 1988. FLOCH, J. M. Identités visuelles. Paris: Presses Universitaires de France, 1995. GERALDI, J. W. O texto na sala de aula: leitura e produção. São Paulo: Ática, 1984. GONÇALVES, A. V. Gêneros textuais e reescrita: uma proposta de intervenção interativa. 2007. 344f. Tese (Doutorado em Linguística e Língua Portuguesa) - Faculdade de Ciências e Letras de Araraquara, Universidade Estadual Paulista, Araraquara, 2007.

GONÇALVES, A. V. Ferramentas didáticas e ensino: da teoria à prática de sala de aula. In: NASCIMENTO, E.L. (Org.) Gêneros textuais: da didática das línguas aos objetos de ensino. São Carlos: Editora Claraluz, 2009.p. 225-248.

GONÇALVES, A. V.; BAZARIM, M. (Org.). Interação, gêneros e Letramento: a (re)escrita em foco. São Carlos: Claraluz, 2009.

MARCUSCHI, L. C. A perspectiva interacionista sócio-discursiva de Bronckart. In: MEURER, J.L.; BONINI, A.; MOTTA-TOTH, D. (Org.). Gêneros, Teorias, Métodos e Debates. São Paulo: Parábola, 2005.

MARCUSCHI, L. C. Produção textual, análise e compreensão. São Paulo: Parábola Editorial, 2008.

MACHADO, A. R. Por uma concepção ampliada do trabalho do professor. In: MACHADO, A. R; GUIMARÃES, A. M. de; M.; COUTINHO, A. (Org.). O interacionismo sociodiscursivo: questões epistemológicas e metodológicas. Campinas: Mercado de Letras, 2007, p. 77-101. 
NASCIMENTO, E. L. Gêneros da atividade, gêneros textuais: repensando a interação em sala de aula. In: (Org.). Gêneros Textuais: da didática da língua aos objetos de ensino. São Carlos: Claraluz, 2009, p. 51-91.

NEVES, M.H.M. Gramática na escola. São Paulo: Contexto, 1997.

NEVES, M.H.M. Gramática de usos do português. São Paulo: UNESP, 2000.

NEVES, M. H. M. Uma introdução ao funcionalismo: proposições, escolas, temas e rumos. In: CRHISTIANO, M. E. A.; SILVA, C. R.; HORA, D. (Org.). Funcionalismo e gramaticalização: teoria, análise e ensino. João Pessoa: Idéia, 2004, p. 13-28.

NEVES, M.H.M. A Gramática funcional. São Paulo: Martins Fontes, 2004.

NEVES, M.H.M. Texto e gramática. São Paulo: Contexto, 2006.

PARANÁ, Secretaria do Estado da Educação. Secretaria do Estado da Educação. Superintendência de Educação. Departamento de Ensino Fundamental. Diretrizes Curriculares da educação fundamental da rede de educação básica do Estado do Paraná. Curitiba: 2009.

SÃO PAULO (Estado). Secretaria de Estado da Educação/SEE-SP. 1991. Proposta curricular para o ensino de língua portuguesa no $1^{\circ}$. grau. São Paulo: SEESP/CENP, $4 \mathrm{a}$. ed. ROJO, R. O texto no ensino-aprendizagem de línguas hoje: desafios da contemporaneidade. In: TRAVAGLIA, L. C. et al (Org.). Gêneros de texto: caracterização e ensino. Uberlândia: EDUFU, 2008. p. 9-45.

PINHO, J. B. Propaganda institucional, usos e funçôes da propaganda em relaçôes públicas. São Paulo: Summus, 1990.

SAITO, C. L. N. Nas teias do Homem-Aranha: um estudo do gênero discursivo "adaptação oficial de filme em quadrinhos". 2007. 155 f. Tese (Doutorado em Filologia e Língua Portuguesa) - UNESP-Assis, 2007.

SAITO, C. L. N. Telejornal: um gênero para o letramento midiático. In: NASCIMENTO, E. L. (Org.). Gêneros Textuais: da didática da língua aos objetos de ensino. São Carlos: Claraluz, 2009. p. 195-224.

SCHNEUWLY, B. Les outils de l'enseignant - Un essai didactique. Repères, 22, p. 19-38, 1991.

SCHNEUWLY, B.; DOLZ, J. Gêneros e tipos de discurso: consideraçôes psicológicas e ontogenéticas. In: Gêneros orais e escritos na escola. Trad. e org. de Roxane Rojo e Glaís Sales Cordeiro. Campinas: Mercado de Letras, 2004. p. 21-39.

SCHNEUWLY, B.; DOLZ, J. Gêneros e progressão em expressão oral e escrita: elementos para reflexões sobre uma experiência suíça (francófona). In: SCHNEUWLY. B; DOLZ, J. Gêneros Orais e Escritos na Escola. Trad. de Roxane Rojo e Glaís Sales. Campinas: Mercado de Letras, 2004. 
SILVA, W. R. Estudo da gramática no texto: demandas para o ensino e a formação do professor de língua materna. Maringá: EDUEM, 2010.

TRAVAGLIA, L. C. Gramática e interação: uma proposta para o ensino de gramática no $1^{0}$. e $2^{0}$. graus. São Paulo: Cortez, 1996.

\section{Site consultado}

REVISTA VEJA. Guia para fazer o bem. Edição Especial do ano 34, n. ${ }^{\circ} 51$.

Disponível em: <http://www.veja.com.br/acervodigital/home.asp>.

Recebido em 7 de março de 2010. Aprovado em 8 de setembro de 2010. 


\section{Anexos}

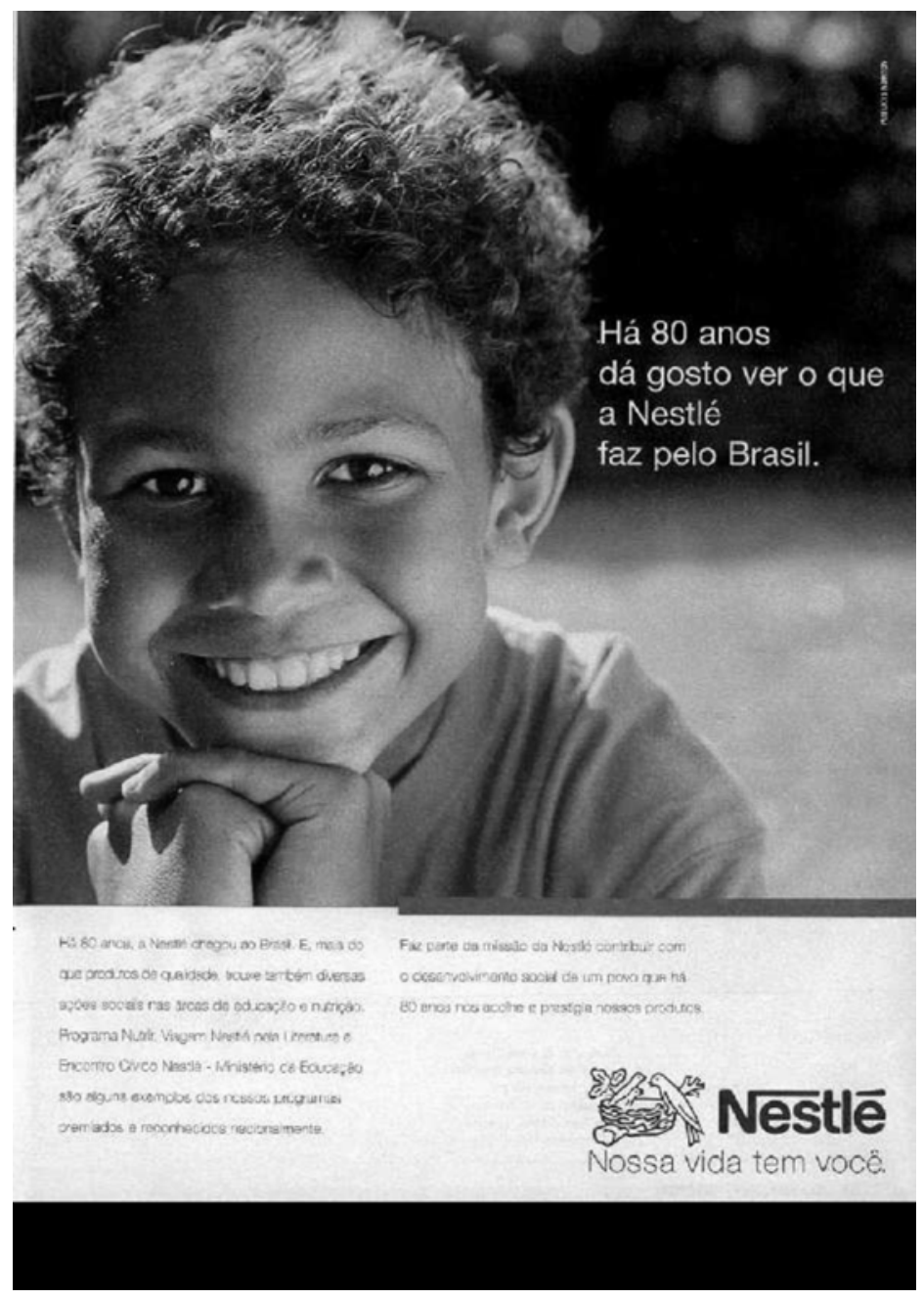



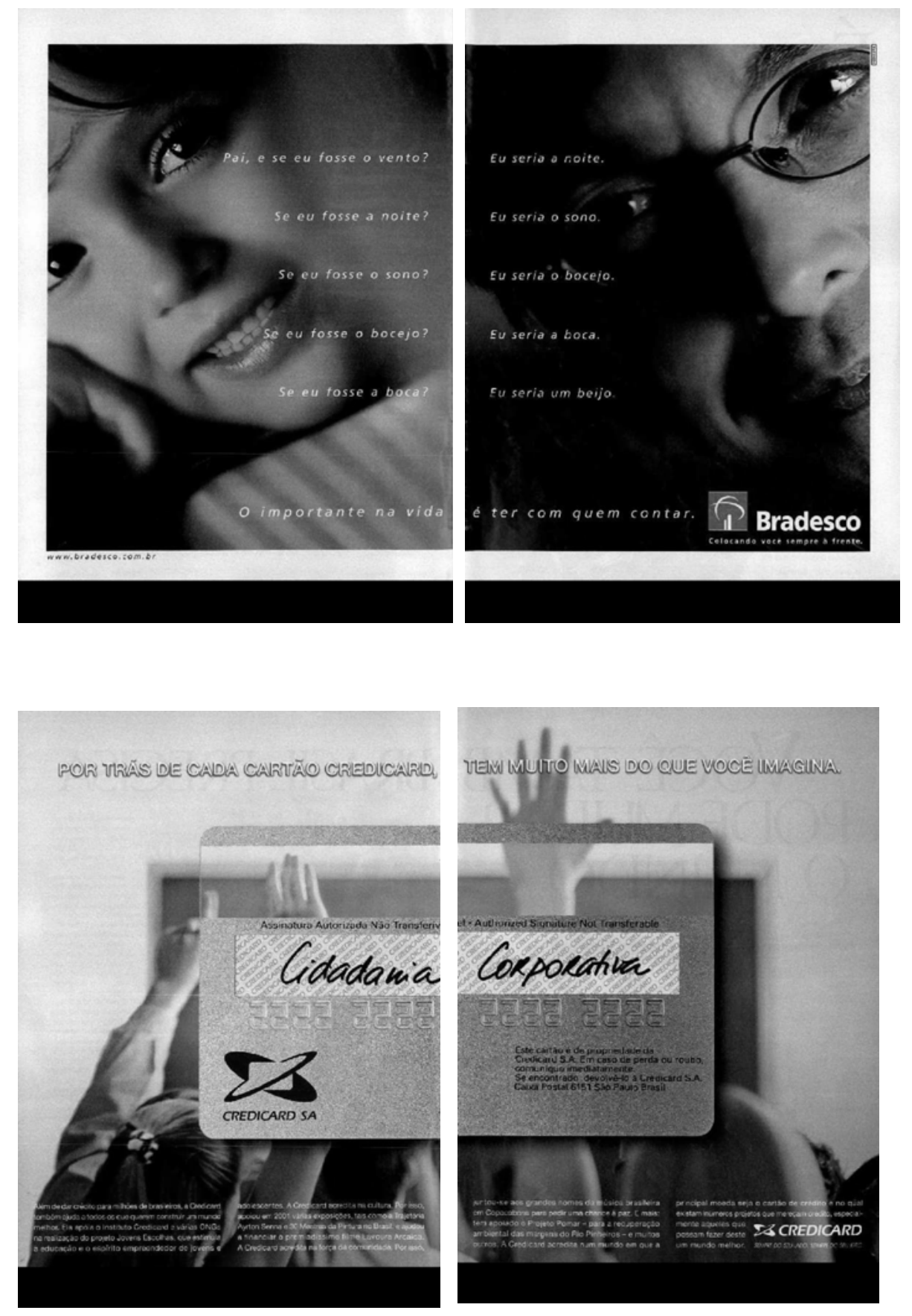


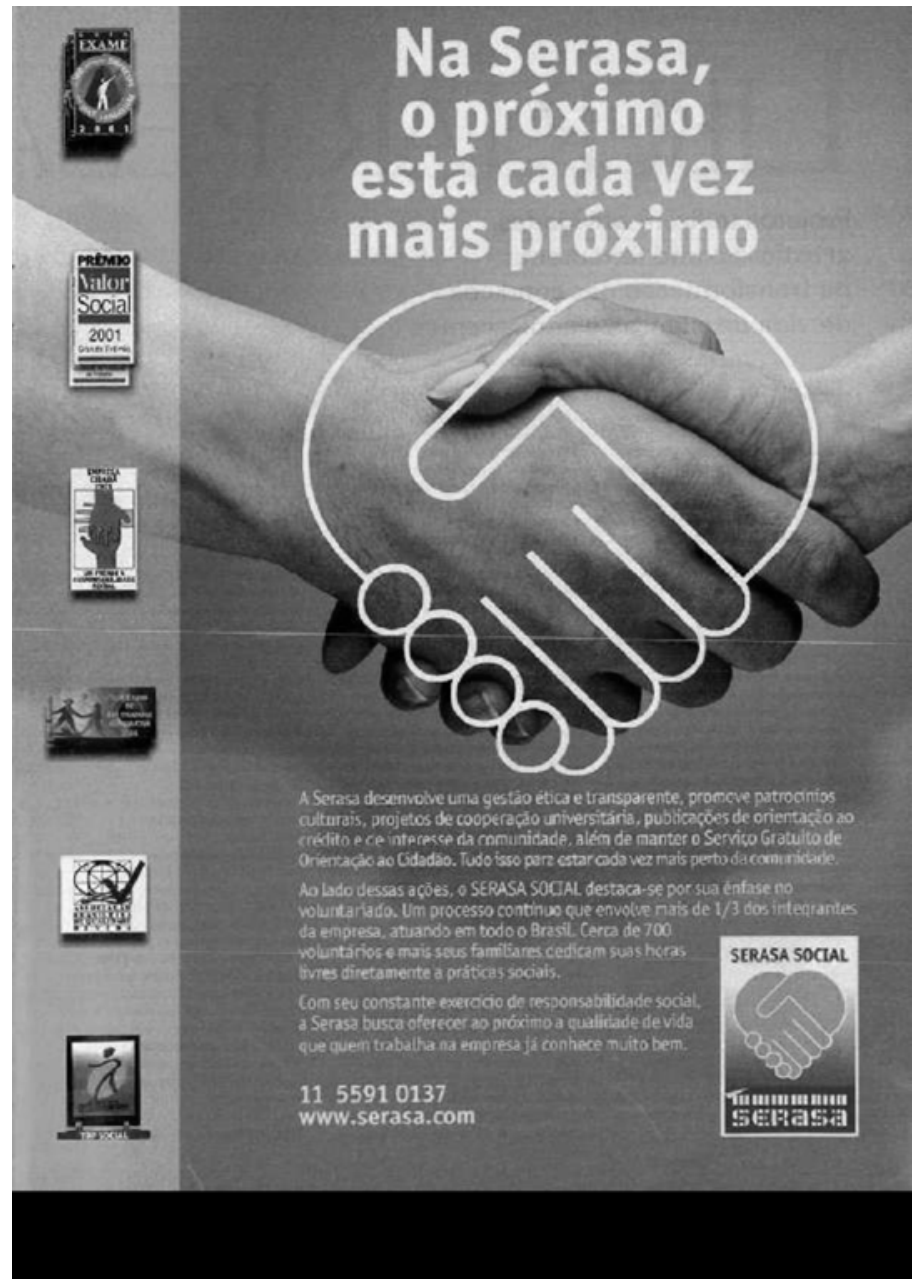




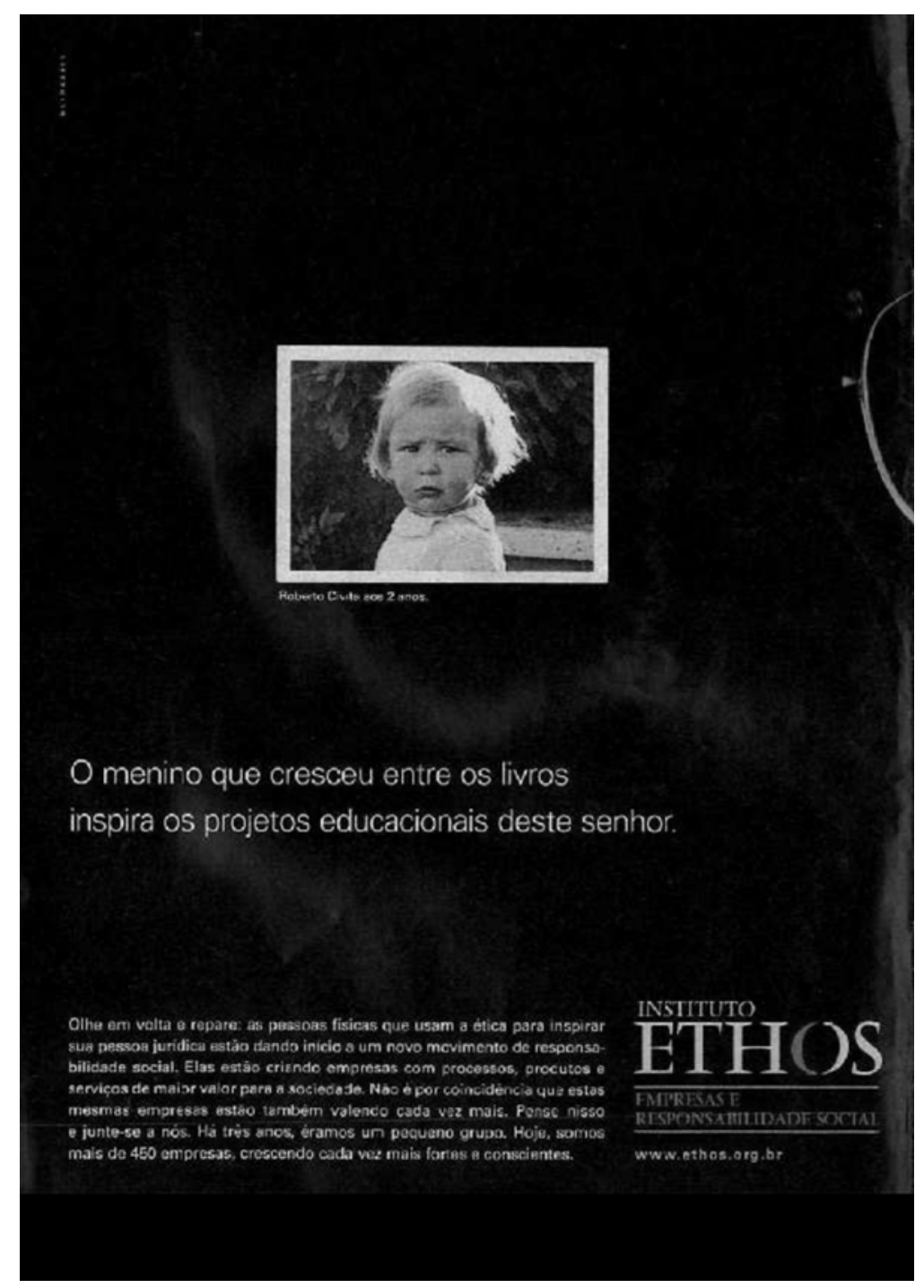

